\title{
Biodegradable Polysaccharide Gels for Skin Scaffolds
}

\author{
Stephen J. Juris ${ }^{1}$, Anja Mueller ${ }^{1}$, Brian T. L. Smith ${ }^{1}$, Samantha Johnston ${ }^{1}$, Robert Walker ${ }^{1}$, \\ Robert D. Kross ${ }^{2}$
}

${ }^{1}$ Central Michigan University, Mt. Pleasant, USA; ${ }^{2}$ Kross Link Labs, Bellmore, USA.

Email: juris1sj@cmich.edu, muell1a@cmich.edu

Received March $2^{\text {nd }}, 2011$; revised May $2^{\text {nd }} 2011$; accepted June $10^{\text {th }}, 2011$.

\begin{abstract}
A variety of skin substitutes are used in the treatment of full-thickness burns. Substitutes made from skin can harbor latent viruses, and artificial skin grafts can heal with extensive scarring, failing to regenerate structures such as glands, nerves, and hair follicles. Biodegradable and biocompatible hydrogels, however, rarely mimic the strength of the epidermis. Therefore, novel and practical skin scaffold materials remain to be developed. Polysaccharides form hydrogels with predicted inherent biocompatibility. This paper describes the preparation and biocompatibility of unique hydrogel skin scaffolds from plant-extracted polysaccharide mixtures of specific sources, types, and molecular weight fractions. These hydrogels have a range of mechanical and degradation properties with the potential to fulfill the multiple, diverse functions of artificial skin, including protection, compatibility with different cell types, biodegradation, and release of needed signals for cell growth and wound healing.
\end{abstract}

Keywords: Hydrogel, Polysaccharides, Skin Scaffold

\section{Introduction}

The skin is the largest organ in the body and serves many important functions, such as protection against infection, immune surveillance, perception of touch, and temperature regulation $[1,2]$. Skin contains two layers: the strong epidermis, which is composed mainly of keratinocytes that form the thick protective layer with hair follicles and glands, and the dermis, which contains many different cell types, including collagen-producing fibroblasts, blood vessel-forming endothelial cells, motor and sensory neurons, and immunoregulatory cells.

When skin is superficially damaged the wound is rapidly repaired. However, when the injury destroys both epidermis and dermis, patients often die from infection or loss of plasma [3]. If patients survive with the help of skin grafts, skin often heals with the formation of scar tissue without the regeneration of some cell types [4-7], including hair follicles and sebaceous glands [8]. Thus, an improved scaffold should release cytokines to promote healing and cell differentiation. Also, artificial skin often contains animal material, such as collagen, which may contain infectious material. Due to these problems, there is a need for improved methods and materials for fabricating artificial skin $[9,10]$. Unfortunately, there are limited biocompatible and biodegradable materials available. Hydrogels have been used as an alternate artificial skin, because good hydration is the most important external factor responsible for optimal wound healing [1114], as water is necessary for transport of nutrients to the growing cells. Hydrogels, however, are commonly not physically strong enough to mimic the tough, thin dermis [9].

The polymer most often used in skin scaffold synthesis is a polyester based on lactic acid (PLA) and glycolic acid (PGA) [15-19]. However, these polyesters have been shown to degrade to their monomeric components, resulting in high local acidity that can destroy proteins [20-22]. Thus, a material that avoids acidity and is capable of delivering bioactive molecules would be more useful.

Polysaccharides are biopolymers with predicted biocompatibility, and many polysaccharides form physical hydrogels [23]. There are also a variety of polysaccharides that form helical structures and thus are stronger materials. In this study, we used four different gelforming polysaccharides: 1 -carrageenan, $\kappa$-carrageenan, xanthan gum, and konjac gum [24-26]. The two carrageenans and xanthan form strong double helical confor- 
mations with specific cations present [27,28], and konjac forms a partially-ordered single helix with the right carbocation [29]. Xanthan and konjac gum are mostly used as thickeners, as are the carrageenans, which are also known to form H-bond-stabilizing reversible gels [23]. Gel formation is a two-step process induced by specific counterions; first the double helices aggregate, then the aggregates combine at a certain combination of temperature and concentration, stiffening the gel. Konjac and xanthan gum gel formation seems to be dependent mostly on ionic strength (which also drives helix formation), concentration, and temperature [24,25].

Polysaccharides may indeed be a useful material as a skin scaffold with the capability of delivering molecules involved in wound healing; some polysaccharides even improve wound healing $[9,30]$. Mostly natural polysaccharides have been investigated as biomaterials, such as chitosan [5,7,31], cellulose [32], collagen [33,34], and hyaluronic acid [35-37]. Chitin/poly(lactic acid-co-glycolic acid) (PGLA) blends [38] and starch-based blends $[39,40]$ have been reported for protein drug delivery and tissue engineering scaffolds, respectively. A crosslinked hyaluronic acid hydrogel has been loaded with bioactive cytokines and successfully induced angiogenesis [36]. This paper reports the preparation of hydrogels made from plant polysaccharides with different mechanical strengths and activities. Mixtures of these extracted polysaccharides have already been used successfully in the development of a skin patch for drug delivery [41].

Developed polysaccharide skin scaffolds are required to be biocompatible, promote healing, and mimic the strength of dermis and epidermis in order to prevent further tissue damage. This skin scaffold will be made of two layers, a dense, strong top layer for keratinocytes mimicking the epidermis, and a porous, softer layer for fibroblasts, mimicking the dermis. This paper reports the testing of biocompatibility and strength of polysaccharides and polysaccharide hydrogels synthesized from plant extracts, as well as their method of preparation.

\section{Materials and Methods}

\subsection{Materials}

EMD Chemicals: HPLC grade water, 30\% hydrogen peroxide; Fisher Scientific: potassium phosphate monobasic and dibasic, potassium chloride $(\mathrm{KCl})$, calcium lactate $\left(\mathrm{C}_{6} \mathrm{H}_{10} \mathrm{CaO}_{6}\right)$, hydrogen chloride $(\mathrm{HCl})$; Sigma: Triton X-100, Bovine Serum Albumin (BSA); TIC Gums: $\kappa$-carrageenan (Colloid $710 \mathrm{H}$ Powder), -carrageenan (Colloid 881 M Powder), Xanthan (Ticaxan Rapid Powder), Konjac (Konjac High Viscosity), Ticagel (121-AGF Powder); Arch Personal Care Produces (ARCH): Cosmocil preservative; Aldrich: sodium benzoate $\left(\mathrm{NaC}_{6} \mathrm{H}_{5} \mathrm{CO}_{2}\right)$,
N-methyl pyrrolidone, glucose $\left(\mathrm{C}_{6} \mathrm{H}_{12} \mathrm{O}_{6}\right)$, glycerin $\left(\mathrm{C}_{3} \mathrm{H}_{5}(\mathrm{OH})_{3}\right)$; Hyclone: Heat inactivated fetal bovine serum; American Type Culture Collection: MeWo human fibroblast cell line; Invitrogen: Minimum Essential Media (MEM), L-glutamine, penicillin/streptomycin, Trypsin/EDTA; Roche Biochemicals: formazan dye WST-1. Water was purified through a Barnstead E-pure filter system and collected at $18 \mathrm{MOhm}$.

\subsection{Instrumentation}

1) UV spectra were obtained on an Agilent $8453 \mathrm{UV} / \mathrm{Vis}$ Spectrometer utilizing Agilent ChemStation software. 2) Gel permeation chromatography was conducted on a Waters Breeze system consisting of a Waters 1515 isocratic pump, 717+ autosampler, and 2414 refractive index detector, a column heater, and with Breeze software, with Fluka polyethylene glycol (PEG) standards on two Tosohaas TSK-Gel $7.5 \mathrm{~mm} \times 30 \mathrm{~cm}$ columns in series, with deionized ultra-filtered (DIUF) water as solvent at $1.0 \mathrm{~mL} / \mathrm{min}$ and $30^{\circ} \mathrm{C}$. 3) IR spectroscopy was performed with $\mathrm{KCl}$ pellets on a Nicolet Magna IR 560 spectrometer. 4) Differential scanning calorimetry (DSC) was carried out at a heating rate of $10^{\circ} \mathrm{C} / \mathrm{min}$ using a TA Instruments Inc. model 2100 with a 2910 DSC cell at 50 $\mathrm{mL} / \mathrm{min}$. 5) Thermal gravimetric analysis (TGA) measurements used a TA Instruments 2950 with a Thermal Analyst 2100 control unit and a $10^{\circ} \mathrm{C} / \mathrm{min}$ heating rate in nitrogen atmosphere. 6) A TAQ800 Dynamic Mechanical Analyzer (DMA) was used for mechanical analysis at a strain ramp from $0.01 \%-0.4 \%$. The modulus was calculated from the slope of the linear region of a stress vs. strain curve. 7) Cell viability, as measured by hydrolysis of the formazan dye WST-1, was measured using a Spectramax microplate spectrometer. Measurements were taken at $450 \mathrm{~nm}$, and the $650 \mathrm{~nm}$ reference absorbance was subtracted from all samples before subtracting media reading from experimental samples.

\subsection{Preparation of the Hydrogels}

Hydrogels were prepared following Dr. Kross' patent [41]. To prepare the "original" hydrogel, konjac gum $(0.168 \mathrm{~g})$, xanthan gum $(0.112 \mathrm{~g})$, $\kappa$-carrageenan $(0.08 \mathrm{~g})$, and $\mathrm{t}$-carrageenan $(0.16 \mathrm{~g})$ were initially dispersed in $\mathrm{N}$-methyl pyrrolidone $(1.2 \mathrm{~g})$, and the mixture was stirred into water $(17.09 \mathrm{~g})$. Potassium chloride $(0.08 \mathrm{~g})$, calcium lactate $(0.16 \mathrm{~g})$, sodium benzoate $(0.02 \mathrm{~g})$, and Cosmocil CQ (0.02 g) were added, and the mixture was stirred until all dissolved. Glucose $(0.90 \mathrm{~g})$ and malic acid $(0.05 \mathrm{~g})$ were mixed initially and then stirred in slowly until the solution became more viscous. The solution was weighed, heated to $85^{\circ} \mathrm{C}$ to initiate gelling, and reweighed. The water lost in heating was re-added to the 
mixture, which was again heated to $85^{\circ} \mathrm{C}$. The gel was then poured into five separate Petri dishes $(5 \mathrm{~cm}$ diameter $)$ in $2 \mathrm{~g}$ quantities and allowed to cool and gel at $4^{\circ} \mathrm{C}$. Gels produced had a thickness of about $0.9 \mathrm{~mm}$, which reduced up to $0.3 \mathrm{~mm}$ over time as water was lost. The variability between the different compositions was +/$0.15 \mathrm{~mm}$.

The preparation of the "alternative" hydrogel also followed the patent [41]. Ticagel 121-AGF Powder $(0.5 \mathrm{~g})$, sodium benzoate $(0.02 \mathrm{~g})$ and Cosmocil CQ $(0.02 \mathrm{~g})$ were added to preweighed glycerin $(1.0 \mathrm{~g})$ and stirred. DIUF water $(18.46 \mathrm{~g})$ was added to the beaker and the mixture stirred until thickened by heating, as above, and the liquid then similarly poured and allowed to gel during cooling.

Variations of the original composition included: $150 \%$ konjac, elimination of $\mathrm{KCl}$, xanthan, one of the carrageenans, or Cosmocil. When the release of Bovine Serum Albumin (BSA) from the gel was to be measured, BSA was added directly to the pre-gel mixture before heating. Variations of the alternate composition included reducing the amount of water. The method for the respective preparations of these mixtures was exactly the same as above.

\subsection{Determination of Relative Hydrogen Bonding Strength}

The broad $-\mathrm{OH}$ absorption peak, present on the spectra at $3000-3500 \mathrm{~cm}^{-1}$, was used to quantify the relative average strength of $\mathrm{H}$-bonding present in the various gels. The calculation involves the initial vertical subdivision of the $-\mathrm{OH}$ peak into $\sim 50 \mathrm{~cm}^{-1}$ increments. The heights of each of these increments from the base of the spectrum to the peak were then measured, in millimeters, and totaled. This sum divided by 100 became the division factor. Beginning at the higher frequency end of the peak, each increment was numbered and the sum then divided by the division factor resulting in a weighted average. This total number was reflective of the degree of overall H-bonding strength. Higher values (lower frequency vibrations) indicate less relative hydrogen bonding strength. If the sample contains - NH bonds as well, only samples with the same amount of $-\mathrm{OH}$ and $-\mathrm{NH}$ peaks can be compared with each other.

\subsection{Cell Culture}

The human fibroblast cell line MeWo was cultured in MEM supplemented with $10 \%$ heat-inactivated fetal bovine serum, $2 \mathrm{mM} \mathrm{L}$-glutamine, $100 \mathrm{U} / \mathrm{ml}$ penicillin, and $100 \mu \mathrm{g} / \mathrm{mL}$ streptomycin. Cells were incubated at $37^{\circ} \mathrm{C}$ in $5 \% \mathrm{CO}_{2}$. Cells were passaged using $0.25 \%$ Trypsin/ EDTA and centrifuged for 5 minutes at $200 x \mathrm{~g}$.

\subsection{Cell Viability Assay}

Individual components of prepared polysaccharide skin scaffolds, except konjac gum and Ticagel (due to insolubility), were tested for toxicity with human fibroblasts by incubating the individual components with $5 \times 10^{4} \mathrm{MeWo}$ cells for either 3 or 7 days. Hydrogels were also tested by cutting formed hydrogels to the diameter of a 96-well plate and incubating them with $5 \times 10^{4}$ MeWo cells for 7 days. The formazan dye WST-1 was used to measure the metabolic activity of cells per manufacturer's instructions. Samples were read at both $450 \mathrm{~nm}$ (sample reading) and $650 \mathrm{~nm}$ (reference). Samples were tested on at least three replicates and the error reported as the standard deviation of the mean of each sample.

\subsection{Primary Skin Irritation in Rabbits}

The Primary Skin Irritation study followed the Organization for Economic Cooperation and Development (OECD) Guidelines for the Testing of Chemicals, Test No. 404 [42], and was performed by Eurofins PSL (725 Cranbury Road, East Brunswick, NJ 08816) [43]. NIH guidelines for the care and use of laboratory animals (NIH Publication \#85-23 Rev. 1985) have been observed. An original gel was prepared under sterile conditions and additionally sterilized with ethanol and stored under moist conditions.

In short, three naïve, male New Zealand albino rabbits (young adults) were kept in controlled conditions for 13 days. A $0.5 \mathrm{~g}, 1 \mathrm{in}^{2}$ piece of the original hydrogel was applied to one $6-\mathrm{cm}^{2}$ intact dose site on each animal. Individual dose sites were scored according to the Draize scoring system [44] at approximately $30-60 \mathrm{~min}, 24,48$, and $72 \mathrm{~h}$, and at 7, 10, and 14 days after patch removal. The resulting Primary Dermal Irritation Index (PDII) was classified as follows: 0 , non-irritating; $>0-2.0$, slightly irritating; $2.1-5.0$, moderately irritating; $>5.0$, severely irritating. The animals were observed for signs of gross toxicity and behavioral changes at least once daily during the test period.

\subsection{Assessment of the Ready Biodegradability of the Original Hydrogel with the Closed Bottle Test}

The assessment of the Ready Biodegradability of the original hydrogel was determined via a standard test for biodegradability [45], and was performed by Eurofins GAB (Eutinger Str. 24, D-75223 Niefern-Öschlebronn, Germany).

In short, closed glass bottles were filled with aerated and inoculated test medium [46]. $\mathrm{O}_{2}$ consumption was measured with an Oximeter and a calibrated electrode. Sodium benzoate at $2 \mathrm{mg} / \mathrm{L}$ was used to check the activ- 
ity of the inoculum. In accordance with the regulations, the biochemical oxygen demand (BOD) for the reference item should be $>60 \%$ of the theoretical oxygen demand (ThOD) within 14 days.

The effluent of the municipal activated sludge plant of Pforzheim/Germany was taken as the inoculum. The degradability of the original hydrogel was determined in an aqueous test solution at a concentration of $2 \mathrm{mg} / \mathrm{L}$, based on dry matter content. The solution was inoculated with a small number of microorganisms from a mixed population and maintained in closed bottles in the dark at a constant temperature between $19.1^{\circ} \mathrm{C}$ and $22.6^{\circ} \mathrm{C}$.

The hydrogel can be assumed to be inhibitory, if in a toxicity test containing both the test item $(2 \mathrm{mg} / \mathrm{L})$ and the reference item $(2 \mathrm{mg} / \mathrm{L})$, less than $25 \%$ degradation occurs, based on the theoretical and chemical oxygen demand (COD). The ThOD of the toxicity control was calculated from the proportionate amounts of ThOD and COD.

The test was performed in closed BOD flasks in single, 2-, and 3-fold test assays for each of the 6 measurement dates $(4,7,11,14,21$, and 28 days). Ultra pure grade water was strongly aerated for $10 \mathrm{~min}$ to achieve oxygen saturation and allowed to stand for $24 \mathrm{~h}$ without aeration at test temperature. The $\mathrm{O}_{2}$ content was measured at the start of the test. Subsequently, each flask was inoculated with $2 \mathrm{~mL}$ of inoculum and the volume was made up to 5 $\mathrm{L}$ with oxygen-saturated water. Oxygen concentrations were measured in one vessel from each treatment group.

The exerted BOD was calculated by subtracting the oxygen concentration $\left(\mathrm{mg} \mathrm{O}_{2} / \mathrm{L}\right)$ of the mean initial inoculum blank from that of the other study groups. Then, the measured values of the corresponding controls were subtracted. This corrected depletion was divided by the concentration $(\mathrm{mg} / \mathrm{L})$ of the test item, to obtain the specific BOD as mg oxygen per $\mathrm{mg}$ test item. The percentage biodegradation was calculated by dividing the specific BOD by the specific oxygen demand, calculated from the molecular formula in accordance with the OECD guideline $\left(\mathrm{BOD}=\mathrm{mg} \mathrm{O}_{2} / \mathrm{mg}\right.$ hydrogel; $\mathrm{COD}=$ chemical oxygen demand of the test item).

\section{Results}

\subsection{Preparation of the Hydrogels}

All gels are based on the mixture of either N-methyl pyrrolidone, konjac gum, xanthan gum, $\kappa$-carrageenan gum, $\mathbf{l}$-carrageenan gum, potassium chloride, calcium lactate, sodium benzoate, Cosmocil CQ, glucose, and malic acid ("Original"); or glycerin, Ticagel, sodium benzoate, and Cosmocil CQ ("Alternate") developed by Dr. Kross [41]. Konjac gum is derived from the Araceae plant family and contains $40 \%$ glucomannan gum ( $\beta 1-4$ man- nose-glucose, 1.6:1 ratio, with $\beta 1-6$ branching). It is used as a thickener as a substitute for gelatin. Xanthan gum is made by the Xanthomonas campestris bacterium. Xanthan contains $\beta 1-4$ mannose, glucose, and glucuronic acid with $\beta 1-3$ branching. Some of the sugars are also acetylated or modified by pyruvate. Carrageenans are water-soluble sulfated galactans with alternating $\beta 1-3-$ and $\beta 1$-4-bonds and some 4-linked 3,6-anhydrogalactose. $\mathrm{t}$-carrageenan and $\kappa$-carrageenan both form gels, but differ in the amount of sulfonation: l-carrageenan is sulfonated on every sugar in the chain, whereas $\kappa$-carrageenan is sulfonated on every second sugar. Both carrageenans form double helices in the presence of salt, $\mathrm{t}$-carrageenan in the presence of $\mathrm{Ca}^{2+}$-ions, $\kappa$-carrageenan in the presence of $\mathrm{K}^{+}$-ions. Ticagel is a mixture of carrageenan and carboxymethyl cellulose. Variations were made by removing components or by reducing or increasing the amount of components.

Cosmocil and sodium benzoate are antimicrobials. $\mathrm{N}$-methyl pyrrolidone, glucose, and glycerin are added to regulate the viscosity. Malic acid is added for $\mathrm{pH}$ adjustment. Glucose has also additional protein-protective properties.

\subsection{Characterization of Physical, Thermal, and Mechanical Properties}

IR spectroscopy was used to analyze the relative amount of hydrogen bonding (the higher the value, the lower the average relative strength of hydrogen bonding). This method is based on the frequency shift in the $\mathrm{OH}$ stretching peak resulting from hydrogen bonding [47]. The integration across the peak reveals a shift to more or less average relative hydrogen bonding strength if the same type of materials (i.e. the same amount of ratio and amount of functional groups) are compared. Differential scanning calorimetry (DSC) was used to measure the glass transition temperature $\left(T_{g}\right)$ and melting point $\left(M_{p}\right)$. Thermal gravimetric analysis (TGA) was used to determine the thermal stability. Discrete melting points in the DSC data indicate the presence of crystalline regions in the otherwise amorphous hydrogels. In general, the TGA graphs show continuous loss of material with increasing heat, but all show distinct rapid loss steps with the percent of gel lost in that step (Tables 1-3). These data indicate that there are distinct regions in the gel that are phase- separated, suggesting that the gel is not homogeneous. The weight of the gels was determined over time to measure water loss. Dynamic mechanical analysis (DMA) was used to determine the mechanical strengths of the prepared hydrogels. Initial results are summarized in Tables 1-3.

The original mixture showed a high Young's modulus, which was comparable to the modulus of contact lenses 
Table 1. Characterization of hydrogels—original with variations in konjac and xanthan gum.

\begin{tabular}{|c|c|c|c|c|c|c|c|}
\hline Mixture & H-bonding (day) & TGA $\left({ }^{\circ} \mathrm{C}\right)$ & $T_{g}\left({ }^{\circ} \mathrm{C}\right)$ & $M_{p}\left({ }^{\circ} \mathrm{C}\right)$ & Modulus in MPa (day) & Poissons Ratio (day) & Weight Loss in $\%$ (day) \\
\hline Original & 690 (d69) & $\begin{array}{c}52(52 \%) \\
183(14 \%)\end{array}$ & -32.2 & -14.19 & $\begin{array}{c}0.02(\mathrm{~d} 3) \\
0.13(\mathrm{~d} 6) \\
24.01(\mathrm{~d} 8)\end{array}$ & $\begin{array}{l}0.04(\mathrm{~d} 6) \\
0.07(\mathrm{~d} 8)\end{array}$ & $\begin{array}{l}34 \%(\mathrm{~d} 6) \\
66 \%(\mathrm{~d} 8)\end{array}$ \\
\hline $\begin{array}{l}\text { Original without } \\
\text { konjac }\end{array}$ & $701(\mathrm{~d} 38)$ & $\begin{array}{c}95(63.5 \%) \\
184(8.6 \%) \\
215(2 \%)\end{array}$ & -21.78 & -7.92 & $\begin{array}{c}\text { Sample broke }(\mathrm{d} 1,2) \\
38.0(\mathrm{~d} 3)\end{array}$ & Sample broke & Sample broke \\
\hline $\begin{array}{l}\text { Original } 150 \% \\
\text { konjac }\end{array}$ & $901(\mathrm{~d} 1)$ & $183(34 \%)$ & NA & NA & $\begin{array}{c}0.014(\mathrm{~d} 1) \\
0.019(\mathrm{~d} 2) \\
\text { Sample broke }(\mathrm{d} 3)\end{array}$ & $\begin{array}{c}\text { Sample broke }(\mathrm{d} 1) \\
0.58(\mathrm{~d} 2) \\
4.92(\mathrm{~d} 3)\end{array}$ & $\begin{array}{l}53 \%(\mathrm{~d} 2) \\
57 \%(\mathrm{~d} 3)\end{array}$ \\
\hline $\begin{array}{l}\text { Original without } \\
\text { xanthan }\end{array}$ & $626(d 17)$ & $\begin{array}{l}47(32.5 \%) \\
180(61 \%)\end{array}$ & -32.14 & Not seen & $\begin{array}{l}0.015(\mathrm{~d} 1) \\
0.019(\mathrm{~d} 2) \\
0.020(\mathrm{~d} 3)\end{array}$ & $\begin{array}{c}\text { Sample broke }(\mathrm{d} 1) \\
7.05(\mathrm{~d} 2) \\
19.61(\mathrm{~d} 3)\end{array}$ & $\begin{array}{l}49 \%(d 2) \\
93 \%(d 3)\end{array}$ \\
\hline
\end{tabular}

NA: Not Available.

Table 2. Characterization of hydrogels—original with variations in $\kappa$ - and $\mathrm{t}$-carrageenan gum.

\begin{tabular}{|c|c|c|c|c|c|c|c|}
\hline Mixture & H-bonding (day) & $\operatorname{TGA}\left({ }^{\circ} \mathrm{C}\right)$ & $T_{g}\left({ }^{\circ} \mathrm{C}\right)$ & $M_{p}\left({ }^{\circ} \mathrm{C}\right)$ & Modulus in MPa (day) & Poissons Ratio (day) & Weight Loss in \% (day) \\
\hline Original & $690(\mathrm{~d} 69)$ & $\begin{array}{c}52(52 \%) \\
183(14 \%)\end{array}$ & -32.2 & -14.19 & $\begin{array}{c}0.02(\mathrm{~d} 3) \\
0.13(\mathrm{~d} 6) \\
24.01(\mathrm{~d} 8)\end{array}$ & $\begin{array}{l}0.04(\mathrm{~d} 6) \\
0.07(\mathrm{~d} 8)\end{array}$ & $\begin{array}{l}34 \%(\mathrm{~d} 6) \\
66 \%(\mathrm{~d} 8)\end{array}$ \\
\hline $\begin{array}{l}\text { Original without } \\
\kappa \text {-carrageenan }\end{array}$ & $698(\mathrm{~d} 33)$ & $\begin{array}{c}69(74 \%) \\
172(10 \%)\end{array}$ & -32.16 & Not seen & $\begin{array}{c}\text { Broke }(\mathrm{d} 1,4) \\
0.019(\mathrm{~d} 2)\end{array}$ & Broke & Broke \\
\hline $\begin{array}{l}\text { Original } 150 \% \\
\kappa \text {-carrageenan }\end{array}$ & $691(\mathrm{~d} 14)$ & $186(25.5 \%)$ & NA & Not seen & $\begin{array}{l}0.024(\mathrm{~d} 1) \\
0.045(\mathrm{~d} 3) \\
21.75(\mathrm{~d} 5)\end{array}$ & $\begin{array}{l}0.30(\mathrm{~d} 3) \\
0.92(\mathrm{~d} 5)\end{array}$ & $\begin{array}{l}23 \%(\mathrm{~d} 3) \\
83 \%(\mathrm{~d} 5)\end{array}$ \\
\hline $\begin{array}{l}\text { Original without } \\
\qquad \mathrm{KCl}\end{array}$ & $727(\mathrm{~d} 34)$ & $183(27 \%)$ & NA & Not seen & $\begin{array}{c}\text { Broke }(\mathrm{d} 1) \\
5.51(\mathrm{~d} 2) \\
12.70(\mathrm{~d} 3)\end{array}$ & $\begin{array}{l}0.91(\mathrm{~d} 2) \\
0.63(\mathrm{~d} 3)\end{array}$ & $\begin{array}{l}88 \%(\mathrm{~d} 2) \\
94 \%(\mathrm{~d} 3)\end{array}$ \\
\hline $\begin{array}{l}\text { Original without } \\
\text { l-carrageenan }\end{array}$ & $713(\mathrm{~d} 29)$ & $\begin{array}{l}69(73.5 \%) \\
179(8.5 \%)\end{array}$ & -32.5 & Not seen & $\begin{array}{l}\text { Broke }(\mathrm{d} 1) \\
0.077(\mathrm{~d} 2) \\
56.21(\mathrm{~d} 3)\end{array}$ & $\begin{array}{l}7.87(\mathrm{~d} 2) \\
5.24(\mathrm{~d} 3)\end{array}$ & $\begin{array}{l}56 \%(\mathrm{~d} 2) \\
82 \%(\mathrm{~d} 3)\end{array}$ \\
\hline $\begin{array}{l}\text { Original without } \\
\text { calcium lactate }\end{array}$ & $716(d 77)$ & $\begin{array}{c}203(5 \%) \\
224(7.5 \%)\end{array}$ & NA & NA & $6.99(\mathrm{~d} 77)$ & NA & NA \\
\hline
\end{tabular}

NA: Not Available.

Table 3. Characterization of hydrogels based on the alternate mixture.

\begin{tabular}{|c|c|c|c|c|c|}
\hline Mixture & H-bonding (day) & TGA $\left({ }^{\circ} \mathrm{C}\right)$ & $T_{g}\left({ }^{\circ} \mathrm{C}\right)$ & $M_{p}\left({ }^{\circ} \mathrm{C}\right)$ & Modulus in $\mathrm{MPa}$ (day) \\
\hline Alternate & 627 & $\begin{array}{l}175(25 \%) \\
263(30 \%)\end{array}$ & NA & NA & 27.68 \\
\hline $\begin{array}{c}\text { Alternate, } 90 \% \mathrm{H}_{2} \mathrm{O} \text {, without } \\
\text { Cosmocil CQ }\end{array}$ & $862(d 4)$ & $\begin{array}{c}57(35 \%) \\
201(15 \%) \\
274(4 \%) \\
773(9 \%)\end{array}$ & -33 & NA & $\begin{array}{c}\text { Broke } \\
2.46(\mathrm{~d} 14)\end{array}$ \\
\hline $\begin{array}{c}\text { Alternate, } 85 \% \mathrm{H}_{2} \mathrm{O} \text {, without } \\
\text { Cosmocil CQ }\end{array}$ & $863(d 4)$ & $\begin{array}{c}74(21 \%) \\
174(11 \%) \\
250(10 \%) \\
266(7 \%)\end{array}$ & NA & NA & $\begin{array}{l}0.06(\mathrm{~d} 18) \\
0.35(\mathrm{~d} 18)\end{array}$ \\
\hline $\begin{array}{c}\text { Alternate, } 80 \% \mathrm{H}_{2} \mathrm{O} \text {, without } \\
\text { Cosmocil CQ }\end{array}$ & 844 & $\begin{array}{c}187(6 \%) \\
267(1.5 \%)\end{array}$ & -33.5 & NA & $0.01(\mathrm{~d} 11)$ \\
\hline
\end{tabular}

NA: Not Available. 
(Table 1). When konjac gum was removed from the mixture, hydrogen bonding strength decreased by a small amount, and the modulus increased by about $50 \%$. These gels required three days to dry at $4^{\circ} \mathrm{C}$ before they could be handled successfully. On the other hand, when the amount of konjac gum was increased by $50 \%$, hydrogen bonding strength and the modulus decreased significantly. Xanthan gum in the mixture increased hydrogen bonding strength, but decreased the modulus significantly. These mixtures also lost water significantly faster than the other hydrogels described so far.

It is unexpected that increased hydrogen bonding strength corresponds to weaker materials. These data could possibly be explained by the amount of water present in the mixture, such that less water leads to a higher modulus. These data correlate well with this explanation, as the modulus increased over time, which was accompanied by weight loss (and with that, water loss).

In the last three mixtures, the weight loss step that occurs around $180^{\circ} \mathrm{C}$ in the TGA became the major step (Table 1). The early weight loss step (observed around $50^{\circ} \mathrm{C}$ ) is still present in the sample without xanthan, but has disappeared from the other mixtures.

When either of the carrageenans was removed from the mixture, the early weight loss step in the TGA was seen again, and in fact the weight loss increased (Table 2). When the amount of $\kappa$-carrageenan was increased or $\mathrm{KCl}$ was removed from the mixture, the higher temperature weight loss step was the only one present. When calcium lactate was removed, this high temperature weight loss step occurred at temperatures above $200^{\circ} \mathrm{C}$ and less weight was lost. These data indicated that this last mixture is the most homogeneous of these gels.

The carrageenans form helices, especially with certain ions present, such as $\mathrm{K}^{+}$as in $\mathrm{KCl}$ for $\kappa$-carrageenan and $\mathrm{Ca}^{2+}$ as in calcium lactate for 1 -carrageenan. Unexpectedly, some of the highest moduli were seen when t-carrageenan or the salts were removed (Table 2). These results, in combination with the TGA data, might indicate that homogeneity increases strength, and that the thermally labile phase is mechanically very stable.

Some of the samples overall also contracted significantly when water was lost and, in extreme cases, this effect was larger than the effect of thinning during extension, yielding unusual Poisson's ratio values.

The alternate mixture has a similar modulus as the original mixture (Table 3). When Cosmocil CQ, an antimicrobial agent that reduces skin cell growth, was removed, the strength of the gels was significantly reduced.

\subsection{Determination of Toxicity of Hydrogel Components and Formed Hydrogels}

The biocompatibility of hydrogel components present in the skin scaffolds was tested by incubating each component with MeWo human fibroblasts for 3 or 7 days. The individual components xanthan gum, $\kappa$-carrageenan, calcium lactate, and sodium benzoate, all demonstrated biocompatibility, with greater than $90 \%$ of the cells remaining viable after 7 days (Figure 1). 1-carageenan demonstrated biocompatibility after 3 days, but was toxic to cells after 7 days (Figure 1). However, after testing the carrageenan components with their proper counterions, l-carrageenan was found to be completely biocompatible (Figure 2). When present as individual components, N-methyl pyrrolidone, Cosmocil CQ, malic acid, and potassium chloride were toxic after 3 days (Figure 1). Glucose and glycerin were slightly toxic to MeWo cells, only allowing for approximately 50\% survival (Figure 1).

Since the antibacterial agent Cosmocil CQ was toxic to MeWo cells at its use concentration, increasing concentrations of the antimicrobial agent sodium benzoate were tested to determine how much could be tolerated by fibroblasts. Whereas $0.25 \%$ sodium benzoate did not affect cell viability, $0.5 \%$ sodium benzoate caused cell toxicity (Figure 3).

In order to test the biocompatibility of hydrogels with human fibroblasts, cut segments of hydrogel were incu-

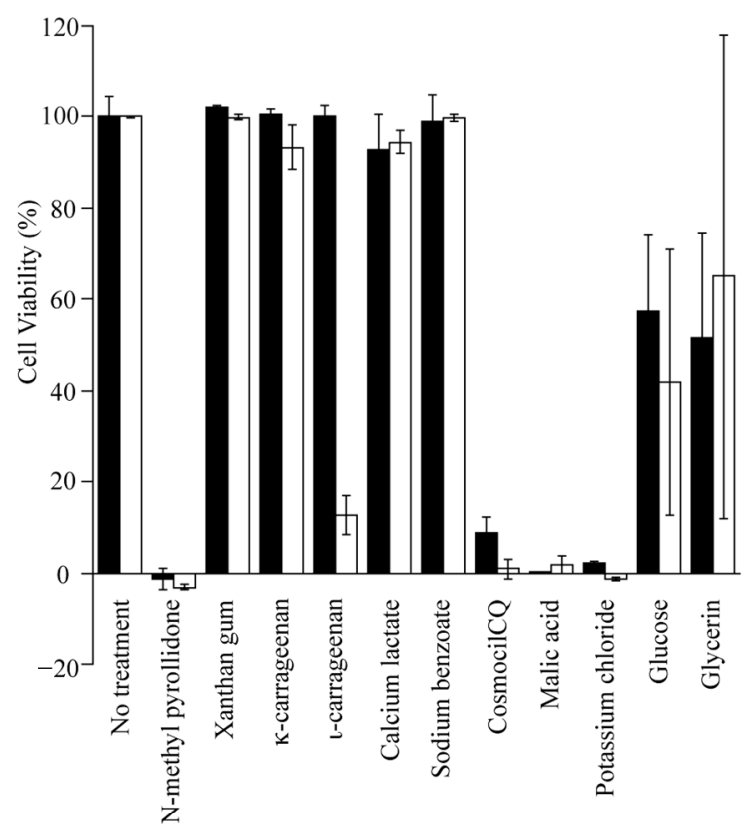

Figure 1. Biocompatibility of individual hydrogel components with human fibroblasts. MeWo human fibroblasts were incubated with individual components at concentrations used in the Original and Alternate hydrogel mixture for either 3 days (black bars) or 7 days (white bars). Cell viability was measured using the formazan dye WST-1 as described in the Experimental section. Error bars represent standard deviation of replicate samples. 


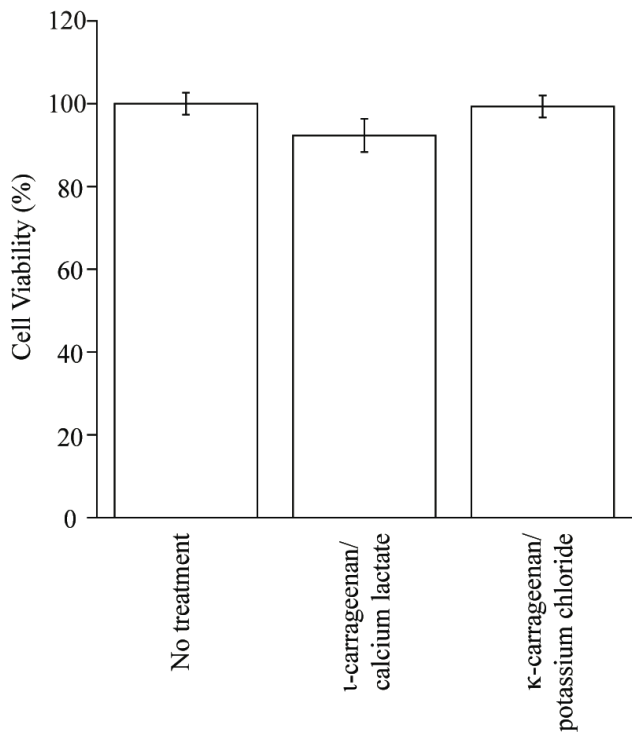

Figure 2. Biocompatibility of carrageenan gums in the presence of their stabilizing counter ion. MeWo human fibroblasts were incubated for 7 days with carrageenan gums in the presence of their counter ions at concentrations used in the Original and Alternate hydrogel mixture. Cell viability was measured using the formazan dye WST-1 as described in the Experimental section. Error bars represent standard deviation of replicate samples.

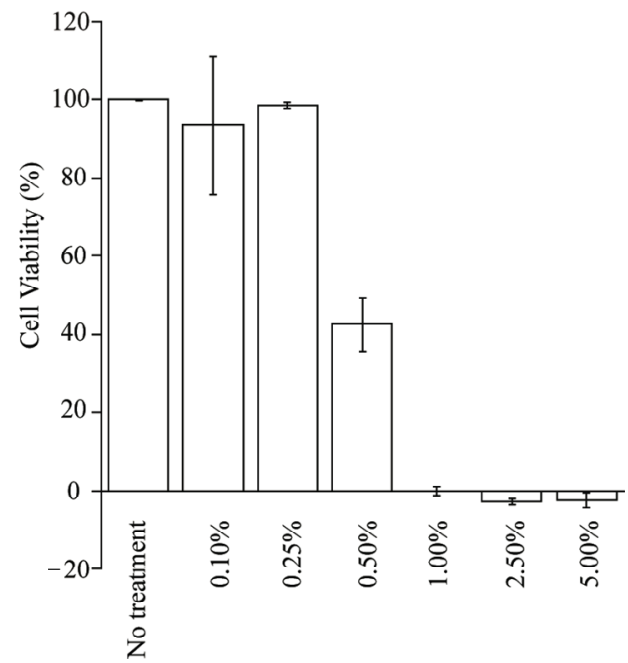

Figure 3. Fibroblast viability in the presence of varied concentrations of sodium benzoate. MeWo human fibroblasts were incubated for 7 days in the presence of increasing concentrations of sodium benzoate. Cell viability was measured using the formazan dye WST-1 as described in the Experimental section. Error bars represent standard deviation of replicate samples.

bated with MeWo human fibroblasts for 7 days. Incubation of MeWo cells with newly formed hydrogels demonstrated that they were not toxic to MeWo cells (Figure 4).

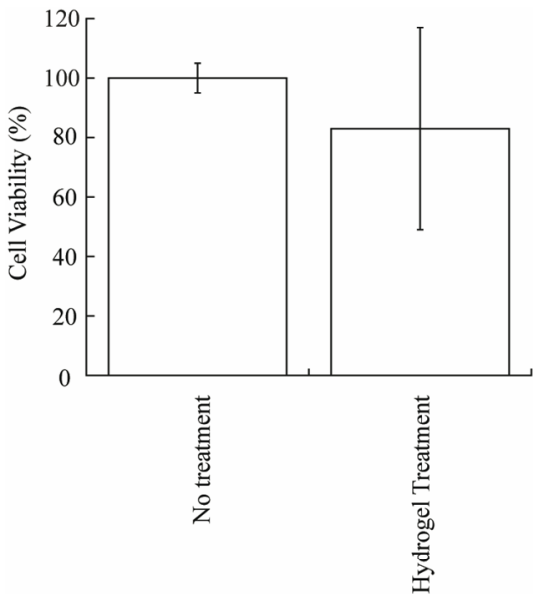

Figure 4. Fibroblast viability in the presence of newly formed hydrogels. MeWo human fibroblasts were incubated for 7 days in the presence of hydrogels cut to the diameter of a 96-well plate well. Cell viability was measured using the formazan dye WST-1 as described in the Experimental section. Error bars represent standard deviation of replicate samples.

\subsection{Primary Skin Irritation in Rabbits}

A primary skin irritation rabbit test was conducted to determine the potential for original hydrogels to produce irritation after a single topical application [43]. Individual skin irritation scores and a summary thereof were used for calculation of Primary Dermal Irritation Index (Table 4).

All animals appeared active and healthy during the study [43]. Apart from the dermal irritation noted below, there were no other signs of gross toxicity, adverse pharmacologic effects, or abnormal behavior. No edema was observed at any treated dose site. One hour after patch removal, very slight erythema was noted for two of three treated sites. The overall incidence and severity of irritation decreased with time. Both affected animals were free of irritation by 48 hours and there was no dermal irritation noted at any site throughout the remainder of the 14day evaluation period. The Primary Dermal Irritation Index for the original polysaccharide hydrogels is 0.3 [44]. Under the conditions of this study the polysaccharide hydrogels are classified as slightly irritating to the skin.

\subsection{Assessment of Ready Biodegradability of the Original Hydrogel}

Degradation was determined by measuring dissolved oxygen over a 28-day period [46] using the "Closed Bottle Test", a standard test for biodegradability by OECD [45] and the EPA. The amount of oxygen taken up by the microbial population during biodegradation of the test item, corrected for uptake by the blank inoculum run in 
Table 4. Incidence and severity of skin irritation in rabbits.

\begin{tabular}{cccc}
\hline \multirow{2}{*}{$\begin{array}{c}\text { Time after Patch } \\
\text { Removal }\end{array}$} & \multicolumn{2}{c}{ Incidence of Irritation } & $\begin{array}{c}\text { Severity of } \\
\text { Irritation-Mean }\end{array}$ \\
\cline { 2 - 4 } 30 - 60 minutes & $2 / 3$ & $0 / 3$ & 0.7 \\
24 hours & $1 / 3$ & $0 / 3$ & 0.3 \\
48 hours & $0 / 3$ & $0 / 3$ & 0.0 \\
72 hours & $0 / 3$ & $0 / 3$ & 0.0 \\
7 days & $0 / 3$ & $0 / 3$ & 0.0 \\
10 days & $0 / 3$ & $0 / 3$ & 0.0 \\
14 days & $0 / 3$ & $0 / 3$ & 0.0 \\
\hline
\end{tabular}

parallel, was expressed as a percentage of the Chemical Oxygen Demand (COD). Sodium benzoate, at $2 \mathrm{mg} / \mathrm{L}$ was used as a degradable reference, along with a toxicity control with original hydrogel and $2 \mathrm{mg} / \mathrm{L}$ sodium benzoate.

The COD was determined to be $2.11 \mathrm{mg} \mathrm{O}_{2} / \mathrm{mg}$ for the original hydrogel, presuming that no nitrification would occur, and based on a dry matter of $9.3 \%$ [46]. The ThOD of the sodium benzoate was calculated to be $1.67 \mathrm{mg}$ $\mathrm{O}_{2} / \mathrm{mg}$, and the ThOD of the mixture of sodium benzoate plus the test item was $1.89 \mathrm{mg} \mathrm{O}_{2} / \mathrm{mg}$. Biodegradation data are shown in Table 5. In 28 days, $83.4 \%$ of the original hydrogel was degraded.

\section{Discussion}

A variety of plant polysaccharide hydrogels were characterized. The data showed that hydrogels can be made with very different mechanical properties, which are needed for the two skin scaffold layers as well as peptide delivery particles within them. The strength, though, is highly dependent on the drying time. Most of these hydrogels do not become brittle but tough upon drying; in fact, some of the strongest biodegradable hydrogels known are being reported. This effect is currently being studied in detail. Both $1-$ and $\kappa$-carrageenan have a double helical structure that is dependent on the presence of the counter ion. The packing of these helices is likely the major source of strength of these hydrogels. The data suggest that the hydrogels are composites, with konjac and xanthan gum as the amorphous matrix, with the carrageenans as fiber reinforcements. The strongest materials were achieved when only k-carrageenan was used as the fiber reinforcement. The trends will be further investigated in more detail.

The TGA data clearly demonstrate that the hydrogels are not homogeneous, indicating that some of the carrageenan is present in the ordered, helical structure. The TGA step percentages in Table 1 do not total 100\% be-
Table 5. Biodegradation of the original hydrogel using the closed bottle test.

\begin{tabular}{cccc}
\hline \multirow{2}{*}{$\begin{array}{c}\text { Time } \\
\text { (days) }\end{array}$} & \multicolumn{3}{c}{ Percent Degradation } \\
\cline { 2 - 4 } & Original Hydrogel & $\begin{array}{c}\text { Sodium } \\
\text { Benzoate }\end{array}$ & $\begin{array}{c}\text { Toxicity } \\
\text { Control }\end{array}$ \\
\hline 4 & 14.5 & 58.7 & 17.8 \\
7 & 28.5 & 64.7 & 40.0 \\
11 & 46.2 & 73.4 & 43.7 \\
14 & 56.2 & 69.5 & 62.6 \\
21 & 68.1 & 71.7 & 76.4 \\
28 & 83.4 & 85.2 & 86.8 \\
\hline
\end{tabular}

cause a portion of the hydrogel volatilizes in a slow, continuous manner. These data indicate that only some of the hydrogel is ordered and the remainder is a homogeneous mix. Two melting points were seen; it is assumed that these result from "crystallized" or, more precisely, ordered water in the hydrogel.

The DMA data show some unusually high moduli for these hydrogels. In some cases, these are several times higher than those for contact lenses, which are some of the strongest known biodegradable hydrogels. The gels were measured shortly after preparation, and then after several days at $4^{\circ} \mathrm{C}$. In most cases, the strength increases considerably after drying. This trend is being investigated in detail; IR spectroscopy is being used to determine changes in relative hydrogen bonding strength and for comparison with further DMA results.

Most of the individual components of the hydrogels were found non-toxic to human fibroblasts. Although several individual components, as single entities, were toxic to MeWo cells, including N-methyl pyrrolidone, a necessary component for hydrogel strength, newly formed hydrogels containing the same concentration of these toxic compounds were deemed biocompatible. The toxicity of aged hydrogels is currently being investigated because they may degrade over time and release these toxic components. If aged hydrogels are toxic, due to degradation and release of toxic components, omission of individual components may aid in the prolonged biocompatibility of hydrogel mixtures. These data suggest that hydrogels formed in the manner described above are biocompatible with human fibroblasts and thus may also be biocompatible with keratinocytes.

Skin irritation determined by the OECD standard rabbit test was slightly irritating during the first 24 hours, but not irritating after that. It is possible that this initial slight irritation results from ethanol used for sterilization.

Hydrogels were also found to be readily biodegradable based on the OECD standard microbial test. In 28 days, 
$83.4 \%$ of the original hydrogel was degraded.

Preparation of hydrogels with different mechanical properties will allow for the development of both dermis and epidermis mimics. The permeability, degradation kinetics, and vascularization potential of these hydrogels, along with the utilization of hydrogels by fibroblasts for migration and extracellular matrix deposition, are currently being investigated.

\section{Acknowledgements}

We are very grateful for the donation of gums from TIC gums and for funding from Central Michigan University.

\section{REFERENCES}

[1] E. Fuchs and S. Raghavan, "Getting under the Skin of Epidermal Morphogenesis," Nature Reviews Genetics, Vol. 3, No. 3, 2002, pp. 199-209.

doi: $10.1038 / \operatorname{nrg} 758$

[2] J. Kanitakis, "Anatomy, Histology and Immunohistochemistry of Normal Human Skin," European Journal of Dermatology, Vol. 12, No. 4, 2002, pp. 390-399.

[3] P. Martin, "Wound Healing-Aiming for Perfect Skin Regeneration," Science, Vol. 276, No. 5309, 1997, pp. 75-81. doi:10.1126/science.276.5309.75

[4] S. T. Boyce, "Design Principles for Composition and Performance of Cultured Skin Substitutes," Burns, Vol. 27, No. 5, 2001, pp. 523-533. doi:10.1016/S0305-4179(01)00019-5

[5] R. Odessey, "Addendum: Multicenter Experience with Cultured Epidermal Autograft for Treatment of Burns," Journal of Burn Care and Rehabilitation, Vol. 13, No. 1, 1992, pp. 174-180. doi:10.1097/00004630-199201000-00038

[6] M. R. Pittelkow and R. E. Scott, "New Techniques for the in Vitro Culture of Human Skin Keratinocytes and Perspectives on Their Use for Grafting of Patients with Extensive Burns," Mayo Clinic Proceedings, Vol. 61, No. 10, 1986, pp. 771-777.

[7] J. S. Williamson, C. F. Snelling, P. Clugston, I. B. Macdonald and E. Germann, "Cultured Epithelial Autograft: Five Years of Clinical Experience with Twenty-Eight Patients," The Journal of Trauma, Vol. 39, No. 2, 1995, pp. 309-319. doi:10.1097/00005373-199508000-00020

[8] C. A. Jahoda, R. F. Oliver, A. J. Reynolds, J. C. Forrester and K. A. Horne, "Human Hair Follicle Regeneration Following Amputation and Grafting into the Nude Mouse," Journal of Investigative Dermatology, Vol. 107, No. 6, 1996, pp. 804-807. doi:10.1111/1523-1747.ep12330565

[9] D. W. Hutmacher, K. W. Ng and H. L. Khor, "Skin Tissue Engineering, Part I - Review," In: R. L. Reis and J. S. Roman Eds., Biodegradable Systems in Tissue Engineering and Regenerative Medicine, CRC Press, Boca Raton, 2005, pp. 601-625.

[10] J. Mansbridge, "Tissue-Engineered Skin Substitutes," Expert Opinion on Biological Therapy, Vol. 2, No. 1, 2002, pp. 25-34. doi:10.1517/14712598.2.1.25

[11] B. S. Atiyeh, J. Ioannovich, C. A. Al-Amm and K. A. El-Musa, "Management of Acute and Chronic Open Wounds: The Importance of Moist Environment in Optimal Wound Healing," Current Pharmaceutical Biotechnology, Vol. 3, No. 3, 2002, pp. 179-195. doi: $10.2174 / 1389201023378283$

[12] B. S. Atiyeh, J. Ioannovich, C. A. Al-Amm, K. A. ElMusa and R. Dham, "Improving Scar Quality: A Prospective Clinical Study," Aesthetic Plastic Surgery, Vol. 26, No. 6, 2002, pp. 470-476. doi:10.1007/s00266-002-2019-5

[13] L. L. Bolton, K. Monte and L. A. Pirone, "Moisture and Healing: Beyond the Jargon," Ostomy Wound Management, Vol. 46, No. Suppl 1A, 2000, pp. 51S-62S.

[14] G. D. Winter and J. T. Scales, "Effect of Air Drying and Dressings on the Surface of a Wound," Nature, Vol. 197, No. 4862, 1963, pp. 91-92. doi:10.1038/197091b0

[15] P. Mainil-Varlet, P. Rahn and S. Gogolewski, "LongTerm in-Vivo Degradation and Bone Reaction to Various Polylactides 1. One-Year Results," Biomaterials, Vol. 18, No. 3, 1997, pp. 257-266. doi:10.1016/S0142-9612(96)00126-3

[16] J. C. Meredith and E. J. Amis, "LCST Phase Separation in Biodegradable Polymer Blends: Poly(D,L-Lactide) and Poly(E-Caprolactone)," Macromolecular Chemistry and Physics, Vol. 201, No. 6, 2000, pp. 733-739. doi:10.1002/(SICI)1521-3935(20000301)201:6<733::AID -MACP733>3.0.CO;2-5

[17] A. M. Reed and D. K. Gilding, "Biodegradable Polymers for Use in Surgery-Poly(glycolic)/poly(lactic acid) Homo-and Copolymers: 2. In-Vitro Degradation," Polymer, Vol. 22, No. 4, 1981, pp. 494-498. doi:10.1016/0032-3861(81)90168-3

[18] D. Tian, Ph. Dubois, R. Jerome and Ph. Teyssie, "Macromolecular Engineering of Polylactones and Polylactides. 18. Synthesis of Star-Branched Aliphatic Polyesters Bearing Various Functional End Groups," Macromolecules, Vol. 27, No. 15, 1994, pp. 4134-4144. doi:10.1021/ma00093a015

[19] M. Vert, S. M. Li, G. Spenlehauer and P. Guerin, "Bioresorbability and Biocompatibility of Aliphatic Polyesters," Journal of Materials Science: Materials in Medicine, Vol. 3, No. 6, 1992, pp. 432-436. doi:10.1007/BF00701240

[20] K. Fu, A. M. Klibanov and R. Langer, "Protein Stability in Controlled-Release Systems," Nature Biotechnology, Vol. 18, No. 1, 2000, pp. 24-26. doi:10.1038/71875

[21] K. Fu, D. W. Pack, A. M. Klibanov and R. Langer, "Visual Evidence of Acidic Environment Within Degrading Poly(Lactic-co-Glycolic Acid) (PLGA) Microspheres," Pharmaceutical Research, Vol. 17, No. 1, 2000, pp. 100106. doi:10.1023/A:1007582911958

[22] C. G. Pitt, M. M. Gratzl, G. L. Kimmel, J. Surles and A. Schindler, "Aliphatic Polyesters: II. The Degradation of Poly(D,L-lactide), Poly(E-caprolactone), and their Copolymers in Vivo," Biomaterials, Vol. 2, No. 4, 1981, pp. 


\section{5-220. doi:10.1016/0142-9612(81)90060-0}

[23] M. Rinaudo, "Advances in Characterization of Polysaccharides in Aqueous Solution and Gel State," In: S. Dumitriu Ed., Polysaccharides: Structural Diversity and Functional Versatility, Marcel Dekker, New York, 2005, pp. 237252.

[24] J. O. Carnali, "Gelation in Physically Associating Biopolymer Systems," Rheologica Acta, Vol. 31, No. 5, 1992, pp. 399-412. doi:10.1007/BF00701120

[25] N. Ikawa, "Mechanical Relaxation of Hydrogel. IV. Dynamic Viscoelastic Properties of Konjac Mannan Gum," Bulletin of the Faculty of Agriculture-Meiji University, Vol. 70, 1985, pp. 33-43.

[26] M. Rinaudo, R. Auzely, C. Vallin and I. Mullagaliev, "Specific Interactions in Modified Chitosan Systems," Biomacromolecules, Vol. 6, No. 5, 2005, pp. 2396-2407. doi:10.1021/bm0580025

[27] T. Sato, T. Norisuye and H. Fujita, "Double-Stranded Helix of Xanthan: Dimensional and Hydrodynamic Properties in 0.1 M Aqueous Sodium Chloride," Macromolecules, Vol. 17, No. 12, 1984, pp. 2696-2700. doi: $10.1021 / \mathrm{ma} 00142 \mathrm{a} 043$

[28] F. van de Velde and G. A. De Ruiter, "Carrageenan," In: A. Steinbuechel and S. K. Rhee Eds., Polysaccharides and Polyamides in the Food Industry: Properties, Production, and Patents, Wiley-VCH, Verlag, Weinheim, 2005, pp. 85-114.

[29] T. Yui and K. Ogawa, "X-ray Diffraction Study of Polysaccharides," In: S. Dumitriu Ed., Polysaccharides: Structural Diversity and Functional Versatility, Marcel Dekker, New York, 2005, pp. 99-122.

[30] M. Thanou and H. E. Junginger, "Pharmaceutical Applications of Chitosan and Derivatives," In: S. Dumitriu Ed., Polysaccharides: Structural Diversity and Functional Versatility, Marcel Dekker, New York, 2005, pp. 661-678.

[31] G. G. Gallico, N. E. O'Connor, C. C. Compton, O. Kehinde and H. Green, "Permanent Coverage of Large Burn Wounds with Autologous Cultured Human Epithelium," New England Journal of Medicine, Vol. 311, No. 7, 1984, pp. 448-451. doi:10.1056/NEJM198408163110706

[32] M. Bootman and R. Yamamoto, Integra Lifesciences I, Ltd., assignee, "Polyurethane-Biopolymer Composite," USA Patent, 6,596, 293. 2000 07/22/03.

[33] A. G. A. Coombes, E. Verderio, B. Shaw, X. Li, M. Griffin and S. Downes, "Biocomposites of Non-Crosslinked Natural and Synthetic Polymers," Biomaterials, Vol. 23, No. 10, 2002, pp. 2113-2118. doi:10.1016/S0142-9612(01)00341-6

[34] D. Wisser and J. Steffes, "Skin Replacement with a Collagen Based Dermal Substitute, Autologous Keratinocytes and Fibroblasts in Burn Trauma," Burns, Vol. 29, No. 4, 2003, pp. 375-380.
[35] H. Li, Y. Liu, X. Z. Shu, S. D. Gray and G. D. Prestwich, "Synthesis and Biological Evaluation of a Cross-Linked Hyaluron-Mitomycin C Hydrogel," Biomacromolecules, Vol. 5, No. 3, 2004, pp. 895-902. doi: $10.1021 / \mathrm{bm} 034463 \mathrm{j}$

[36] R. A. Peattie, A. P. Nayate, M. A. Firpo, J. Shelby, R. J. Fisher and G. D. Prestwich, "Stimulation of In Vivo Angiogenesis by Cytokine-Loaded Hyaluronic Acid Hydrogel Implants," Biomaterials, Vol. 25, No. 14, 2004, pp. 2789-2798. doi:10.1016/j.biomaterials.2003.09.054

[37] X. Z. Shu, Y. Liu, F. S. Palumbo, Y. Luo and G. D. Prestwich, "In Situ Crosslinkable Hyaluron Hydrogels for Tissue Engineering," Biomaterials, Vol. 25, No. 7-8, 2004, pp. 1339-1348. doi:10.1016/j.biomaterials.2003.08.014

[38] F. L. Mi, S. S. Shyu, Y. M. Lin, Y. B. Wu, C. K. Peng and Y. H. Tsai, "Chitin/PLGA Blend Microspheres as a Biodegradable Drug Delivery System: A New Delivery System for Protein," Biomaterials, Vol. 24, No. 27, 2003, pp. 5023-5036. doi:10.1016/S0142-9612(03)00413-7

[39] J. F. Mano, N. M. Neves and R. L. Reis, "Mechanical Characterization of Biomaterials," In: R. L. Reis and J. S. Roman Eds., Biodegradable Systems in Tissue Engineering and Regenerative Medicine, CRC Press, Boca Raton, 2005, pp. 152-174.

[40] M. P. Pavlov, J. F. Mano, N. M. Neves and R. L. Reis, "Fibers and 3D Mesh Scaffolds from Biodegradable Starch-Based Blends: Production and Characterization," Macromolecular Bioscience, Vol. 4, No. 8, 2004, pp. 776-783. doi:10.1002/mabi.200400002

[41] R. D. Kross, "Method for Using Glycol Additives to Texturally Modify Natural Gum Hydrogels," USA Patent, 6,664,301, 2003.

[42] OECD, “OECD Principles of GLP," ENV/MC/CHEM, Vol. 404, OECD, Paris, 1997.

[43] J. Durando, "Primary Skin Irritation Study in Rabbits: Eurofins PSL," 2010, Report nr 28823.

[44] J. H. Draize, G. Woodward and H. O. Calvery, "Methods for the Study of Irritation and Toxicity of Substances Applied Topically to the Skin and Mucous Membranes," Journal of Pharmacology and Experimental Therapeutics, Vol. 82, No. 3, 1944, pp. 377-390.

[45] OECD, "Ready Biodegradability: Closed Bottle Test," OECD Guideline for Testing of Chemicals, Vol. 301D, 2003.

[46] D. Detlef, “Assessment of the Ready Biodegradability of Polysaccharide Hydrogel with the Closed Bottle Test: Eurofins GAB," 2010.

[47] R. Silverstein, G. Bassler and T. Morrill, "Spectrometric Identification of Organic Compounds," John Wiley \& Sons, New York, 1991. 